\title{
Laser-Induced Conversion of Au Powders to Highly Stable Nanoparticles with a Narrow Size Distribution
}

Jeeyoung Lee and Myeongkyu Lee*

Department of Materials Science and Engineering, Yonsei University, Seoul 120-749, Korea

SUPPORTING INFORMATION

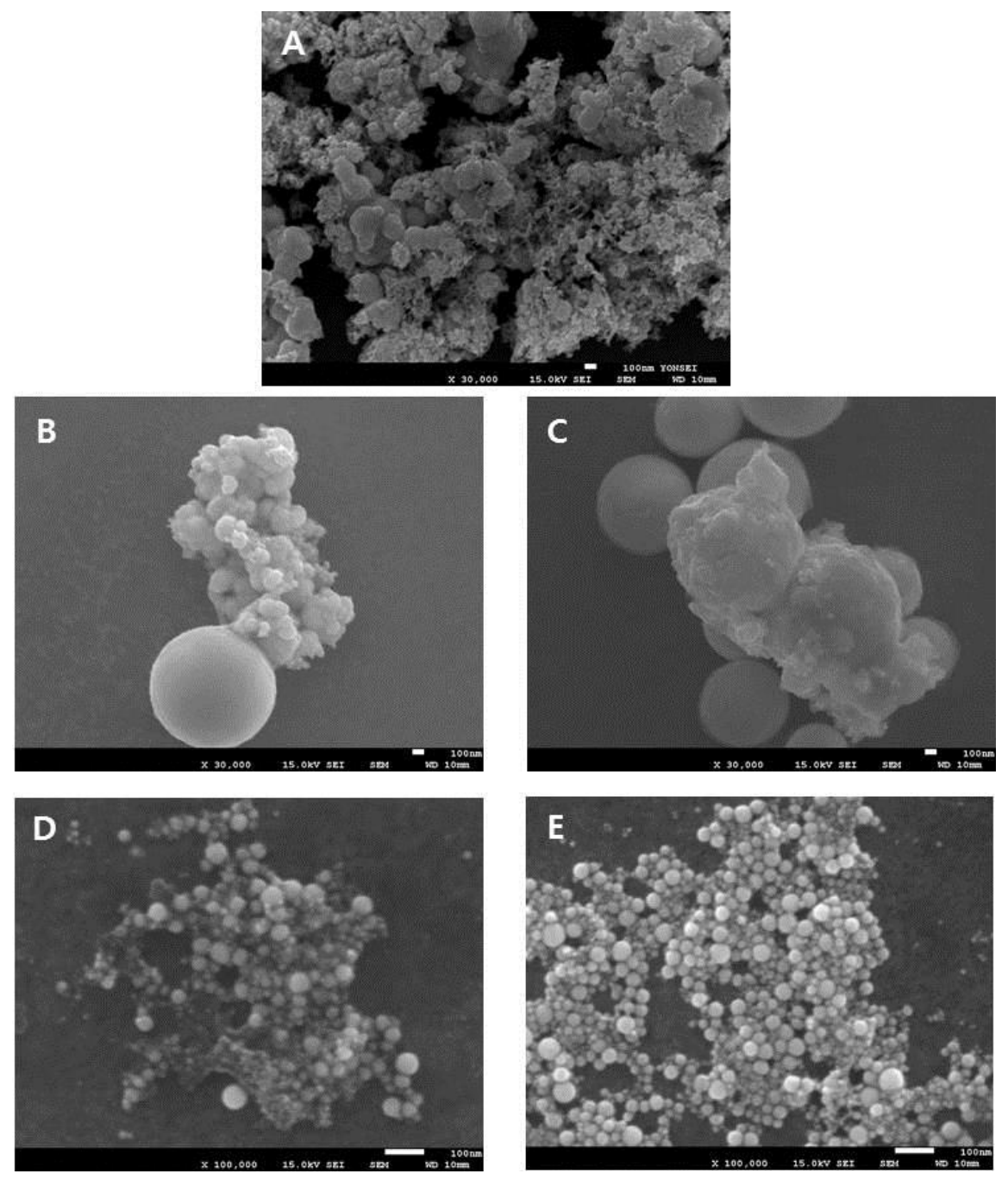

Figure S1 SEM images of Au particles. A: before irradiation, B: after irradiation for 1 min with $532 \mathrm{~nm}$ pulses, C: after irradiation for $5 \mathrm{~min}$ with $532 \mathrm{~nm}$ pulses. D: after irradiation for $1 \mathrm{~min}$ with $1064 \mathrm{~nm}$ pulses, E: after irradiations for $5 \mathrm{~min}$ with $532 \mathrm{~nm}$ pulses and then for $30 \mathrm{~s}$ with $1064 \mathrm{~nm}$ pulses. Pulse energies were $250 \mathrm{~mJ}$ at $532 \mathrm{~nm}$ and $650 \mathrm{~mJ}$ at $1064 \mathrm{~nm}$ and the pulse repetition rate was $10 \mathrm{~Hz}$ at both wavelengths. 

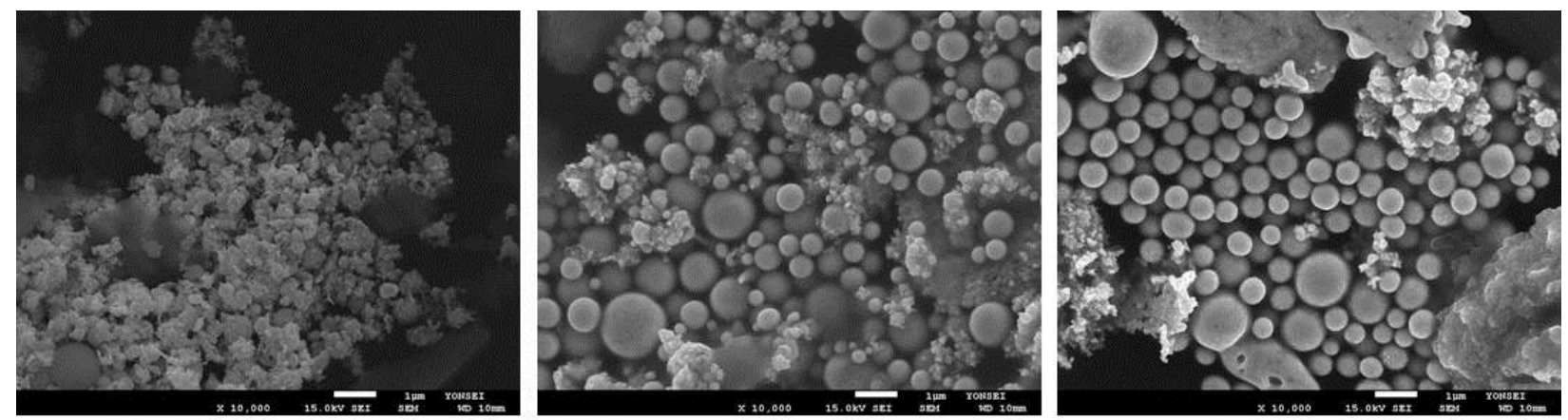

Increasing irradiation time

Figure S2 A sequence of the particle morphologies obtained at a $532 \mathrm{~nm}$ pulse energy of $150 \mathrm{~mJ}$. The images were obtained after $0 \mathrm{sec}$ (left), $30 \mathrm{sec}$ (middle), and $5 \mathrm{~min}$ (right), respectively. Since $150 \mathrm{~mJ}$ was a near-threshold pulse energy, some clusters still remained after $5 \mathrm{~min}$ irradiation. However, when the pulse energy was increased to $250 \mathrm{~mJ}$, only spherical particles were observed after $5 \mathrm{~min}$.
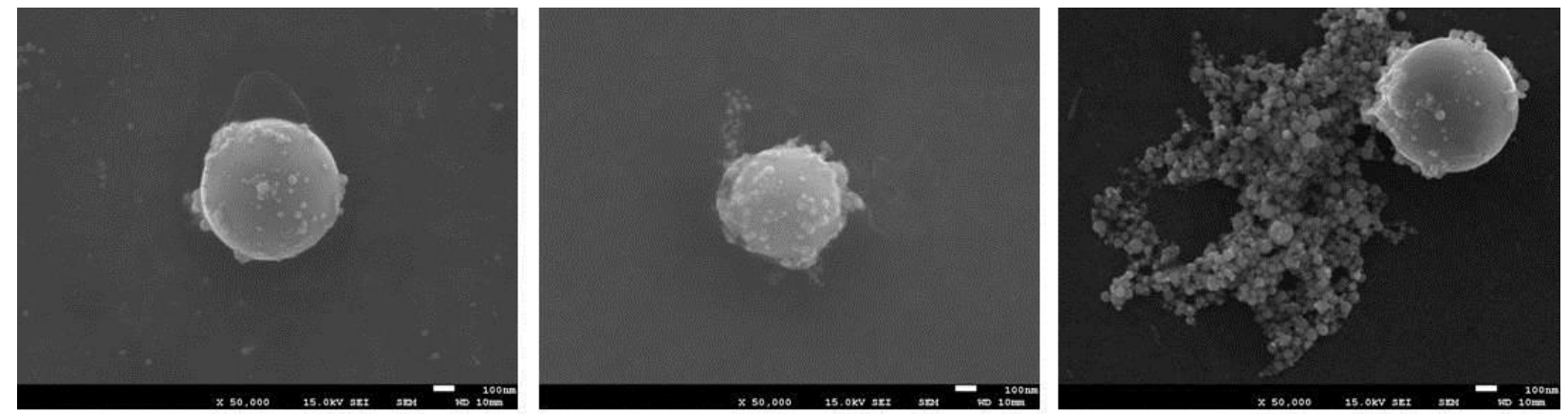

Increasing irradiation time

Figure S3 SEM images showing the evaporation of a large spherical particle by $1064 \mathrm{~nm}$ pulses and condensation into smaller nanoparticles. The condition of a preceded laser irradiation at 532 $\mathrm{nm}$ was $5 \mathrm{~min}$ at pulse energy of $250 \mathrm{~mJ}$. 
(a)

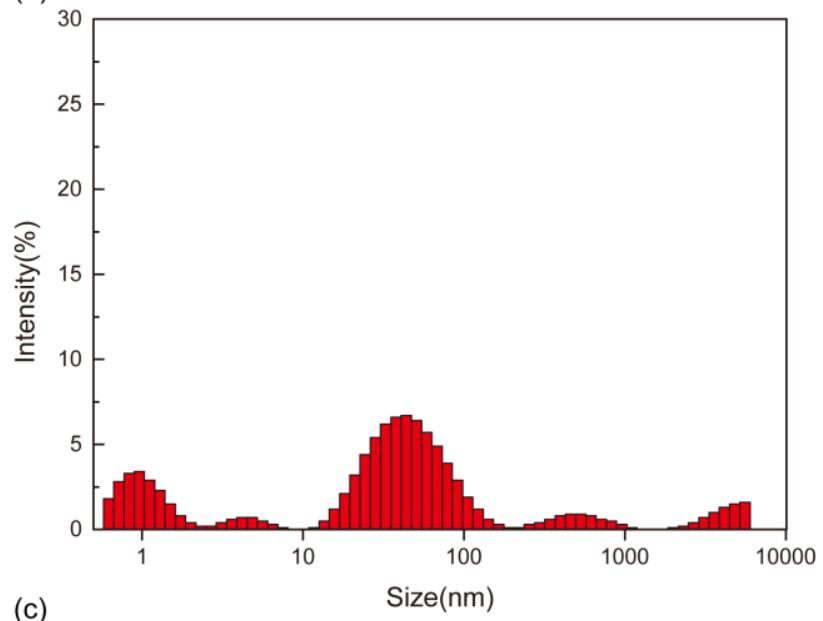

(c)

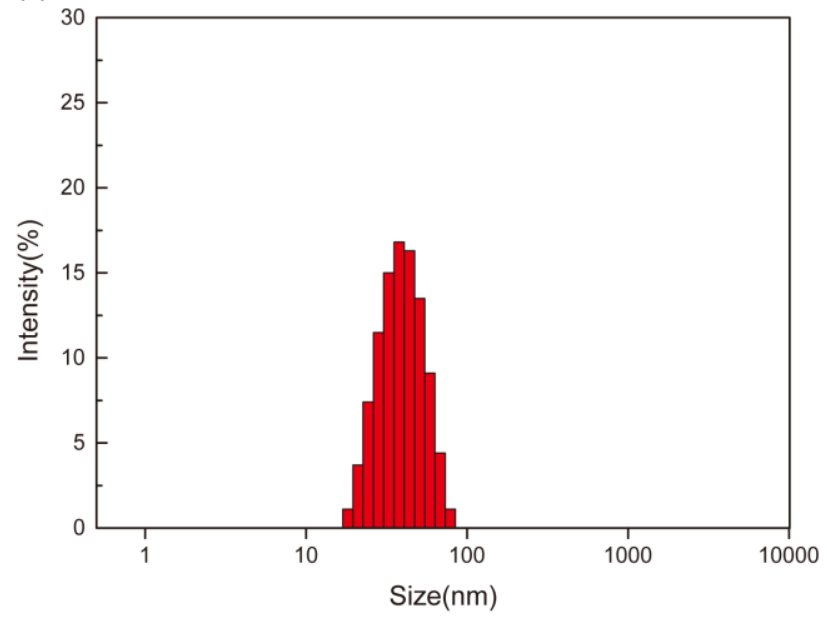

(b)

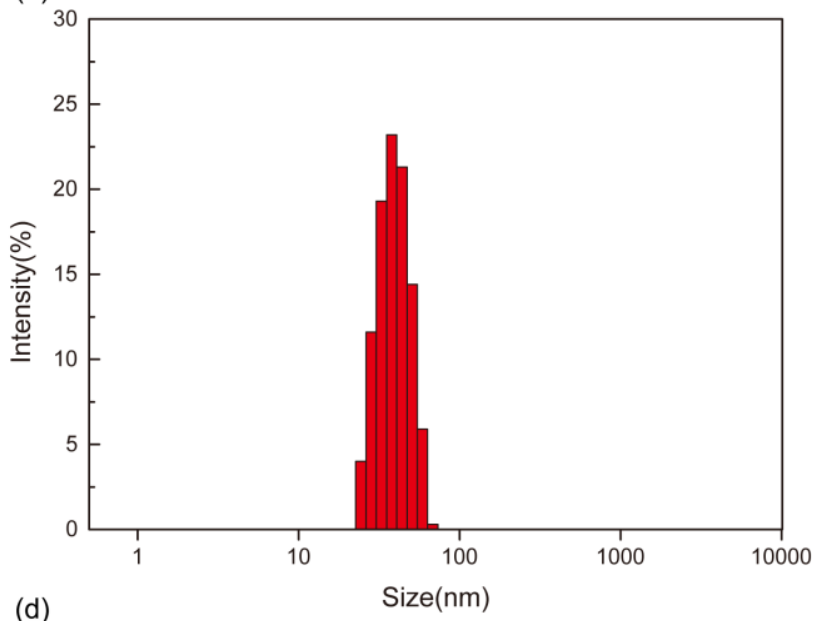

(d)

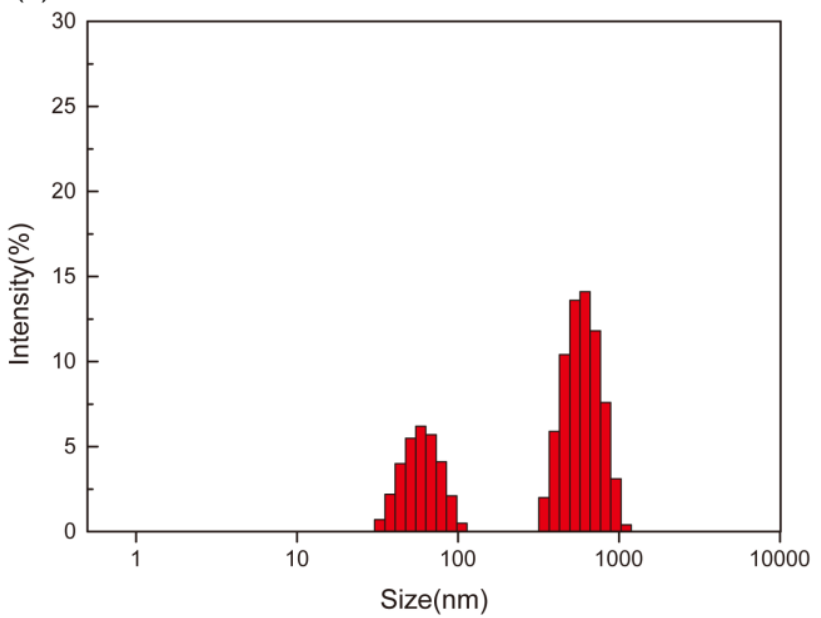

Figure S4 Size distribution of the laser produced gold nanoparticles, measured from dynamic light scattering (DLS). (a) after irradiation for 5 min with $532 \mathrm{~nm}$ pulses, (b) after irradiations for 5 min with $532 \mathrm{~nm}$ pulses and then for $30 \mathrm{~s}$ with $1064 \mathrm{~nm}$ pulses, (c) after irradiations for 5 min with $532 \mathrm{~nm}$ pulses and then for $60 \mathrm{~s}$ with $1064 \mathrm{~nm}$ pulses and (d) after irradiation for 1 min with $1064 \mathrm{~nm}$ pulses. Pulse energies were $250 \mathrm{~mJ}$ at $532 \mathrm{~nm}$ and $650 \mathrm{~mJ}$ at $1064 \mathrm{~nm}$ and the pulse repetition rate was $10 \mathrm{~Hz}$ at both wavelengths. The $\mathrm{x}$-axis data are plotted on $\log$ scales. The size distributions obtained by DLS were slightly different from those from TEM. The size distributions of Au particles observed from TEM images are given in Figure 4. 

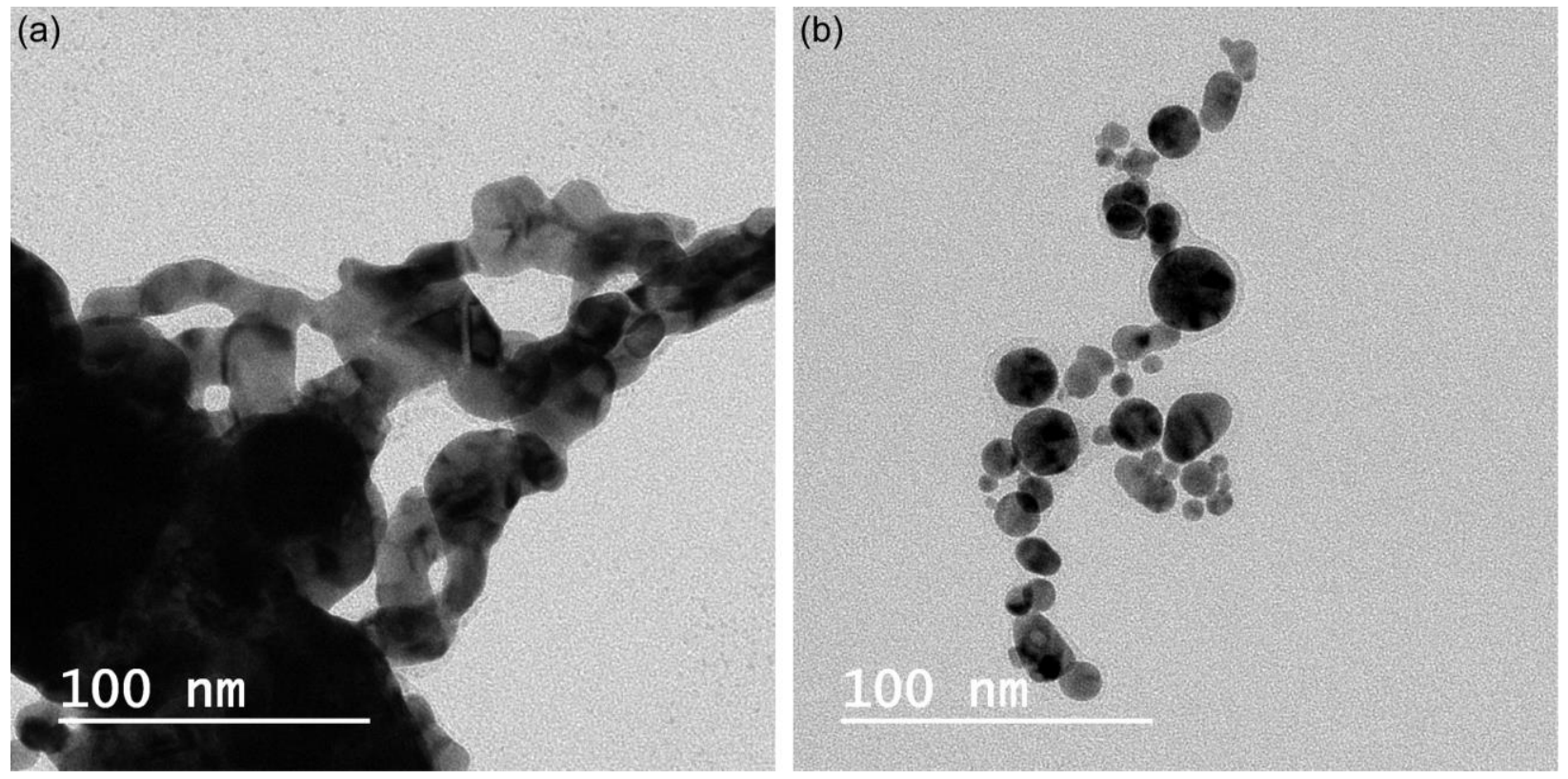

Figure S5 TEM images of (a) gold powders and (b) nanoparticles obtained after laser irradiation. It looked that laser irradiation induced an oxidation layer of about $2 \mathrm{~nm}$ thickness. 